\title{
Comparative study on DPPH free radical scavenging and alpha-glucosidase inhibitory activities of ethanolic extracts from different parts of durian plant (Durio zibethinus Murr.)
}

\author{
${ }^{1,2}$ Evary, Y.M., ${ }^{3, *}$ Nugroho, A.E. and ${ }^{4}$ Pramono, S. \\ ${ }^{1}$ Master of Pharmaceutical Science, Faculty of Pharmacy, Universitas Gadjah Mada, 55821, Indonesia \\ ${ }^{2}$ Department of Pharmacognosy and Phytochemistry, Faculty of Pharmacy, Hasanuddin University, 90245, \\ Makassar, Indonesia \\ ${ }^{3}$ Department of Pharmacology and Clinical Pharmacy, Faculty of Pharmacy Universitas Gadjah Mada, \\ 55821, Yogyakarta, Indonesia \\ ${ }^{4}$ Department of Biology Pharmacy, Faculty of Pharmacy, Universitas Gadjah Mada, 55821, Yogyakarta, \\ Indonesia
}

\author{
Article history: \\ Received: 15 February 2019 \\ Received in revised form: 22 \\ March 2019 \\ Accepted: 27 March 2019 \\ Available Online: 5 April \\ 2019
}

\section{Keywords:}

Durian,

DPPH free radical scavenger, Alpha-glucosidase inhibitor, Extract

DOI:

https://doi.org/10.26656/fr.2017.3(5).085

\begin{abstract}
A study on the discovery of traditional medicine has been done for better health. There are so many potential natural resources from Indonesia which can be used for drug discovery. The current study was aimed to (i) quantify the total phenolic and flavonoid contents; (ii) examine the DPPH free radical scavenging (DFRS) and alphaglucosidase inhibitory (AGI) activities; and (iii) investigate the correlation of the total phenolic and flavonoid contents of different parts of durian plants (Durio zibethinus Murr.) with their activities. Roots, twigs, inner fruit bark and leaves of durian plants (Durio zibethinus Murr.) were macerated with $70 \%$ of ethanol. The total phenolic content was measured using Folin-Ciocalteu assay while the total flavonoid content was measured using colorimetric aluminium trichloride assay. The DFRS and AGI activities were determined in vitro and the results were compared with the total phenolic and flavonoid contents. The root (DR), twig (DT), inner fruit bark (DIFB) and leaves (DL) extracts revealed a difference in DFRS and AGI activities. The root and twig extracts revealed the strongest DFRS activity among the samples evaluated with $\mathrm{IC}_{50}$ values of $18.54 \pm 0.58$ and $96.65 \pm 0.14 \mu \mathrm{g} / \mathrm{mL}$ and alpha-glucosidase inhibitory activity with $\mathrm{IC}_{50}$ values of $0.58 \pm 0.01$ and $1.55 \pm 0.02 \mu \mathrm{g} / \mathrm{mL}$. The root and twig extract also contained the highest phenolic compounds accounting of $94.01 \pm 0.018$ and $31.65 \pm 0.078 \mathrm{mg}$ Gallic Acid Equivalent (GAE)/g dry extract. The total phenolic content of the four extracts has a significant correlation with their DPPH free radical scavenging and alpha-glucosidase inhibitory activity. The different parts of durian plant extracts showed a significant difference $(\mathrm{P}<0.05)$ on the level of phenolic and flavonoid contents and the inhibition concentration against DPPH and alpha-glucosidase enzyme. In this study, it was found that the root and twig extract of Durio zibethinus Murr. can be a potential source to be developed as a new antioxidant by their DPPH free radical scavenging activity and alphaglucosidase inhibitor due to considerable $\alpha$-glucosidase inhibitory activity.
\end{abstract}

\section{Introduction}

Oxidation process as an essential part in aerobic metabolism resulting in radicals which actually needed in the primer immunity response. However, the imbalance of radicals and the existing antioxidant in the body could harm the cells and cause various diseases such as immunodeficiency, heart disease, stroke, diabetes and cancer (Gülçin, 2012). Type II diabetes mellitus which was resulted from unhealthy lifestyle, high carbohydrate consumption, high stress, and reactive oxygen species exposure has been a high prevalence disease. Treatment of this disease was directed to the reduction of postprandial blood glucose levels. An alphaglucosidase inhibitor which inhibits the metabolism of carbohydrate in the intestine has the benefit in reducing blood glucose and lowering diabetes complication risk (Dewi and Maryani, 2015).

Natural antioxidants such as flavonoid and 
phenolic compounds have been proved for their benefit in treating those diseases due to their antioxidant activity (Hay et al., 2004; Kang et al., 2012; Nugroho et al., 2013). Phenolic compounds have the ability to inhibit carbohydrate digestion and absorption. Phenolic compounds also can stimulate insulin secretion from $\beta$ pancreas cells by increasing hepatocellular AMPdependent protein kinase (AMPK) and inhibit the accumulation of lipids in HepG2 cells which can increase glucose levels through gluconeogenesis process (Dey and Lakshmanan, 2013). Quercetin has been proven its ability to repair the proliferation of pancreas cells by inhibiting the cyclin-dependent kinase 1a (cdk1a) expression (Dey and Lakshmanan, 2013). Some research has been conducted to durian (Durio zibethinus Murr.). An examination of the ethanolic extract of durian peels in vivo showed that the extract has the ability to reduce the blood glucose of alloxan-induced diabetic mouse with a dose of $500 \mathrm{mg} /$ Kg BW. It was stated by Muhtadi et al. (2015) that a high dose of durian peels extract is required to achieve hypoglycemia effect. In vitro examination of the methanol extract of Durio kutejensis and Durio dulcis wood bark showed inhibition of alpha-glucosidase enzyme by $63.82 \%$ (in an amount of $5 \mu \mathrm{g} / \mathrm{mL}$ extract) and by $61.90 \%$ (in an amount of $15 \mu \mathrm{g} / \mathrm{mL}$ extract) respectively (Yusro et al., 2016).

Durio zibethinus Murr. is a widely spread species of durian in Indonesia and the root have been traditionally used by Wotu society, South Sulawesi as a traditional medicine to treat diabetes. Besides that, the DFRS activity of ethanolic fruit peels extracts of Durio zibethinus Murr. also has been done and it was revealed that the $\mathrm{IC}_{50}$ value was $372.08 \pm 73.02 \mu \mathrm{g} / \mathrm{mL}$, indicating a low antiradical activity. Therefore, a comparative study was conducted on the DFRS and AGI activities of the different parts of durian extract (Durio zibethinus Murr.) to obtain a proper natural source of antioxidant and antidiabetic agent.

\section{Materials and methods}

\subsection{Chemicals}

Alpha-glucosidase enzyme from Saccharomyces cerevisiae,1,1-diphenyl-2-picrylhydrazyl (DPPH), paranitrophenyl- $\alpha$-D-glucopyranoside(pNPG), acarbose, gallic acids, quercetin, ascorbic acid was purchased from Sigma Aldrich. Sodium carbonate, phosphate buffer, aquabidestillata, Silica thin layer chromatography (TLC) Plate F254, Folin-Ciocalteu, alluminium trichloride $\left(\mathrm{AlCl}_{3}\right)$, boric acid, citric acid, sulphuric acid, acetic acid anhydride, ferry chloride, and sodium acetate were purchased from Merck. Pro analytic grade solvents used were ethyl acetate, ethanol, methanol, chloroform, hexane, toluene and dimethyl sulfoxide (Merck).

\subsection{Plant materials}

The roots, twigs, leaves and inner fruit barks of durian (Durio zibethinus Murr.) were obtained from Wotu, South Sulawesi, Indonesia. The samples were taken on June 2018.

\subsection{Preparation of extract}

Root, twig, leaves and inner fruit bark of durian (Durio zibethinus Murr.) were sorted, cleaned, and dried using oven. Dried samples were ground and macerated with $70 \%$ ethanol for three times. The macerate was collected and concentrated with the rotary evaporator $60^{\circ}$ $\mathrm{C}$ and air-dried until thick extract obtained.

\subsection{Determination of total phenolic content}

The quantitative phenolic content of the extracts was measured using Folin-Ciocalteu assay. Briefly, $2.5 \mathrm{~mL}$ Folin-Ciocalteu $7.5 \%$ and $400 \mu 1$ of samples were mixed and incubated for 8 mins. After the addition of $2 \mathrm{~mL}$ of $5 \%$ sodium hydroxide, the mixture was left for $1 \mathrm{hr}$ at room temperature. The absorbance of each solution was read using spectrophotometer UV-Vis at $653.5 \mathrm{~nm}$. The standard gallic acid $(4-20 \mu \mathrm{g} / \mathrm{mL})$ was plotted to conduct calibration curve. The total phenolic content was expressed in the term of Gallic Acid Equivalents (GAE) in $\mathrm{mg} / \mathrm{g}$ dry extract(Ministry of Health RI, 2012).

\subsection{Determination of total flavonoid content}

The total flavonoid level of the extracts was evaluated using aluminium trichloride colorimetric method. Briefly, $200 \mu \mathrm{L}$ of sample, $1.5 \mathrm{~mL}$ of $95 \%$ of ethanol, $100 \mu \mathrm{L}$ of $10 \%$ aluminium trichloride and 100 $\mu \mathrm{L}$ of $1 \mathrm{M}$ sodium acetate were homogenized with ethanol until the volume reaches $5 \mathrm{~mL}$ in a volumetric flask. The solution was incubated for half an hour. The absorbance of each solution was read spectrophotometrically at $443 \mathrm{~nm}$. The standard calibration curve $(2-10 \mu \mathrm{g} / \mathrm{mL})$ was plotted using quercetin. The total flavonoid content was expressed in the term of Quercetin Equivalents (QE) in $\mathrm{mg} / \mathrm{g}$ dry extract (Ministry of Health RI, 2012).

\subsection{DPPH radical scavenging assay}

Free radical scavenging activity of Durio zibethinus Murr. root, twig, inner fruit bark and leaves extracts were carried out using the DPPH scavenging method. In brief, $16 \mathrm{mg}$ DPPH was dissolved in $250 \mathrm{~mL}$ methanol p.a. and vortexed until completely dissolved. To $100 \mu \mathrm{L}$ of methanolic DPPH solution was added $100 \mu \mathrm{L}$ of sample. The mixture was left at room temperature for half an hour and the absorbance was observed at $515 \mathrm{~nm}$. 
Vitamin $\mathrm{C}$ was the positive control of the measurement. DPPH solution at the same concentration without sample addition was used as the negative control. The measurement was done in triplicate. The DFRS activity of each solution was calculated according to the following equation:

$$
\text { Radical scavenging }(\%)=\frac{A_{\text {control }}-A_{\text {sample }}}{A_{\text {control }}} \times 100 \%
$$

Where $A_{\text {control }}$ was the absorbance of negative control and $\mathrm{A}_{\text {sample }}$ was the absorbance in presence of test or standard sample (Anthony and Saleh, 2013).

\subsection{Alpha-glucosidase inhibitory assay}

The AGI activity was evaluated by measuring the release of 4-nitrophenol from P-nitrophenyl $\alpha$-Dglucopyranoside (pNPG) as the substrate of alphaglucosidase enzyme. The measurements contained 100 $\mu 1$ of phosphate buffer $\mathrm{pH} 6.8,10 \mu \mathrm{L}$ of the $\alpha$ glucosidase enzyme $(0.5 \mathrm{U} / \mathrm{mL})$, and $20 \mu \mathrm{L}$ of sample (extracts or acarbose) in different concentration. The mixture was preincubated for $15 \mathrm{~min}$ at $37^{\circ} \mathrm{C}$. After that $20 \mu \mathrm{L}$ of $5 \mathrm{mM}$ substrate was added and leave for 20 mins at $37^{\circ} \mathrm{C}$. Addition $50 \mu \mathrm{L}$ of $100 \mathrm{mM}$ sodium carbonate was used to end the reaction. The release of $p$ nitrophenol was determined at $404 \mathrm{~nm}$ using microplate reader. The $\%$ inhibition level were calculated using the formula:

$$
\% \text { inhibition }=\frac{A_{\text {control }}-A_{\text {sample }}}{A_{\text {control }}} \times 100 \%
$$

$\mathrm{IC}_{50}$ values were calculated using SPSS 20 version software. The probit score of percent inhibition was plotted with log concentration of inhibitor. All tests were performed in triplicate (Telagari and Hullatti, 2015).

\subsection{Statistical analysis}

All data were shown as mean \pm SEM for at least three replications for each prepared sample. The SPSS ver.20. for windows was used to determine the significant differences of comparisons of each extract evaluated. One-way analysis of variance (ANOVA) followed by Tukey's and Bonferroni test was done. Results with p-value less than 0.05 were considered as statistically significant.

\section{Results and discussion}

\subsection{Determination of total phenolic content}

Phenolics are ubiquitously secondary metabolites present in plants. They have been found to have high antioxidant and antidiabetic activity (Dewi and Maryani, 2015). This assay is a simple method and useful for describing and standardizing natural materials. The total phenolic content of durian root, twig, inner fruit bark and leaves extracts is demonstrated in Table 1. The DR extract revealed the highest total phenolic content at $94.01 \pm 0.018 \mathrm{mg} \mathrm{GAE} / \mathrm{g}$ dry extract, approximately three -fold more than the other three extracts. Khan et al. (2013) previously compare several parts of methanolic white mulberry extracts (flowers, root bark, leaves and stem bark) and found the root bark extract also shown to have a high phenolic content (165 mg GAE/g dry extract). The DT, DIFB, and DL exhibited phenolics compound of $31.65,12.96$, and $27.38 \mathrm{mg}$ GAE/g dry extract, respectively. Statistical analysis of mean of phenolic content of the extracts evaluated revealed significant differences with $p<0.05$. It indicated that the extracts consist of significantly different phenolic content, respectively.

\subsection{Determination of total flavonoid content}

Flavonoids are the widely spread group of plant phenolic compounds, indicated with a benzopyrone structure. The total flavonoid content of the extracts was expressed as quercetine equivalent in milligrams per gram dry extract and showed in Table 1 . The result showed that the DL extract had the highest flavonoid content at a concentration of $2.97 \mathrm{mg}$ QE/g dry extract, followed with DR, DT, DIFB extracts at a concentration of $0.44,0.37$, and $0.25 \mathrm{mg} \mathrm{QE} / \mathrm{g}$ dry extract, respectively. Statistically, the durian root and twig extract showed a closely the same flavonoid content. Nevertheless, the overall extracts contained relatively low flavonoid compounds.

\subsection{DPPH free radical scavenging activity}

The DFRS assay is a fast and simple method to determine the intrinsic ability of an extract or a substance to donate proton or electron to the DPPH radical in a homogenous system (Siriwardhana and Shahidi, 2002). The DFRS activity of the durian part extracts was demonstrated in Table 2. The root and twig extract

Table 1. Total phenolic and flavonoid content of ethanolic extracts from different parts of Durio zibethinus Murr.

\begin{tabular}{cccc}
\hline No. & Samples & Total Phenol $($ mean \pm SEM)* & Total Flavonoid $(\text { mean } \pm \text { SEM })^{* *}$ \\
\hline 1 & DR & $94.01 \pm 0.018^{\mathrm{a}}$ & $0.44 \pm 0.002^{\mathrm{a}}$ \\
2 & DT & $31.65 \pm 0.078^{\mathrm{b}}$ & $0.37 \pm 0.001^{\mathrm{a}}$ \\
3 & DIFB & $12.96 \pm 0.020^{\mathrm{c}}$ & $0.25 \pm 0.031^{\mathrm{b}}$ \\
4 & DL & $27.38 \pm 0.013^{\mathrm{d}}$ & $2.97 \pm 0.001^{\mathrm{c}}$ \\
\hline
\end{tabular}

*Expressed as mg GAE /g extract, **Expressed as mg QE /g extract. Means with different superscript in each column are significantly different at $\mathrm{p}<0.05$ according to Tukey's test $(\mathrm{n}=3)$ 
Table 2. DPPH free radical scavenging and alpha-glucosidase inhibitory activities of ethanolic extracts from different parts of Durio zibethinus Murr.

\begin{tabular}{cccc}
\hline No. & Samples & Antioxidant $\mathrm{IC}_{50}(\mu \mathrm{g} / \mathrm{mL}) \pm$ SEM & Alpha-glucosidase Inhibitory $\mathrm{IC}_{50}(\mu \mathrm{g} / \mathrm{mL}) \pm$ SEM \\
\hline 1 & DR & $18.54 \pm 0.58^{\mathrm{a}}$ & $0.58 \pm 0.01^{\mathrm{a}}$ \\
2 & DT & $96.65 \pm 0.14^{\mathrm{b}}$ & $1.55 \pm 0.02^{\mathrm{a}}$ \\
3 & DIFB & $313.79 \pm 11.81^{\mathrm{c}}$ & $64.43 \pm 1.94^{\mathrm{b}}$ \\
4 & DL & $254.73 \pm 3.56^{\mathrm{d}}$ & No inhibition \\
5 & Vitamin C & $5.05 \pm 0.02$ & - \\
6 & Acarbose & - & 781.63 \\
\hline
\end{tabular}

Means with different superscript in each column are significantly different at $\mathrm{p}<0.05$ according to Tukey's test $(\mathrm{n}=3)$
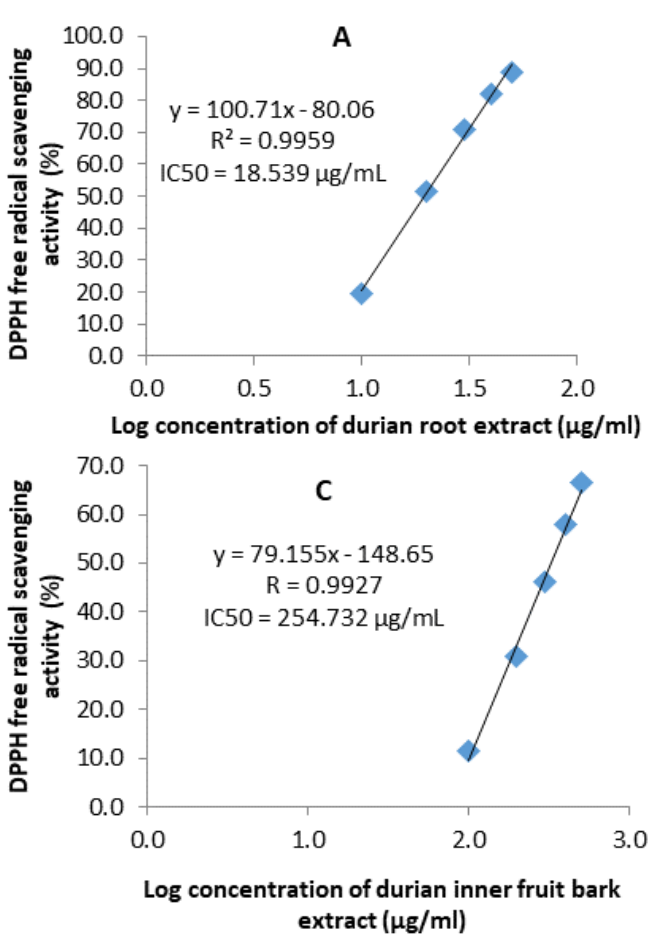

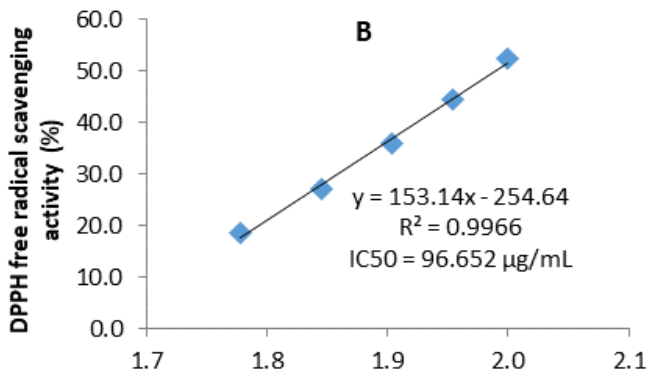

Log concentration of durian twig extract $(\mu \mathrm{g} / \mathrm{ml})$

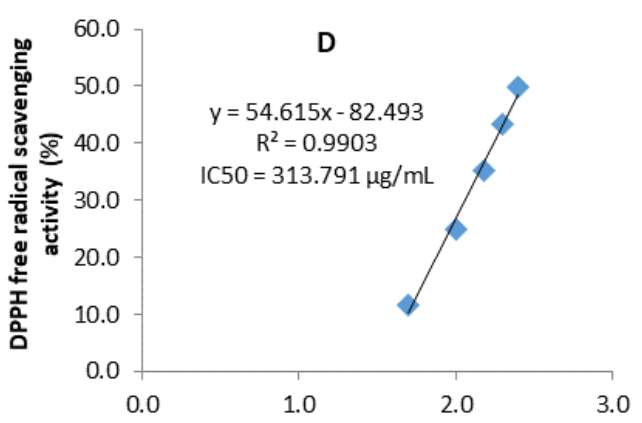

Log concentration of durian leave extract $(\mu \mathrm{g} / \mathrm{ml})$

Figure 1. Relationship between concentration of root (A), twig (B), inner fruit bark, and leave extracts of durian plant with their DPPH free radical scavenging activity

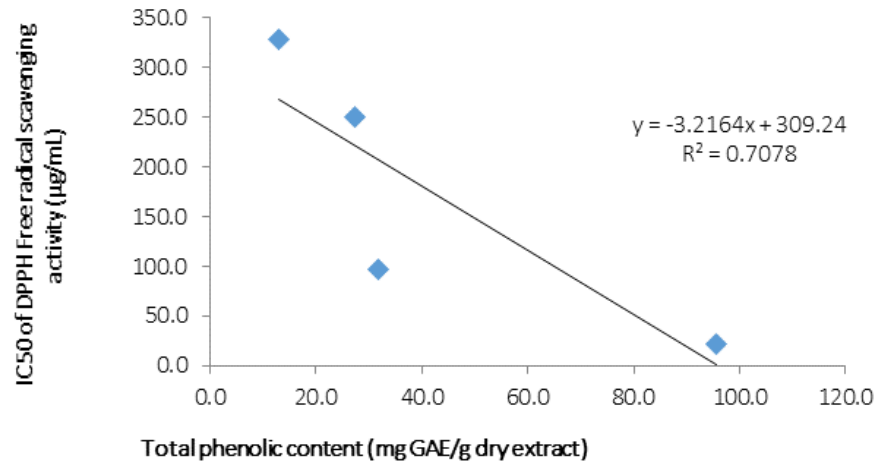

Figure 2. Relationship between DPPH free radical scavenging activity with phenolic content of root, twig, inner fruit bark and leave extract of durian plant
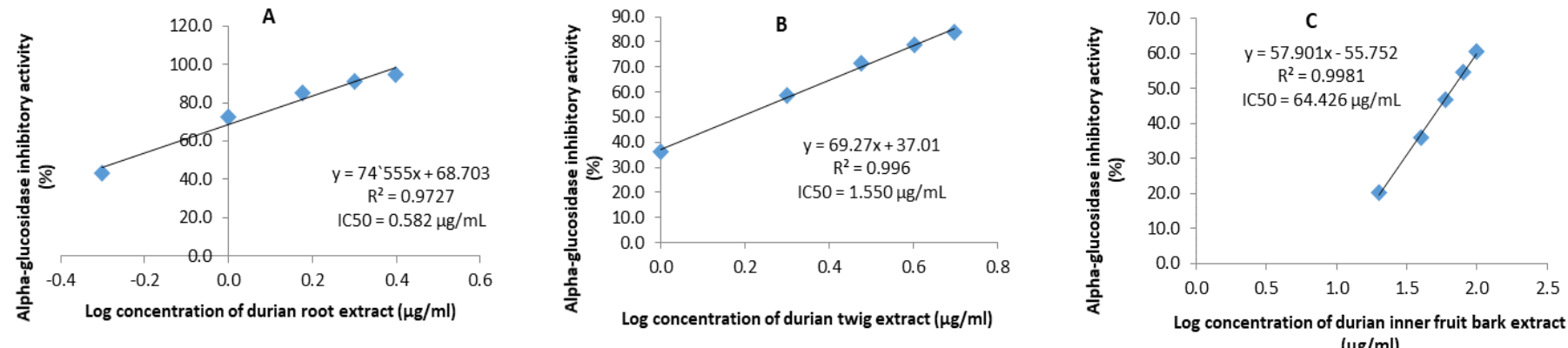

Figure 3. Relationship between concentration of durian root (A), durian twig (B), and durian inner fruit bark (C) extracts of durian plant with their AGI activity. In the measurement, the root extract was used in a range of concentration $(0.5-2.5 \mu \mathrm{g} / \mathrm{mL})$, twig $(1-5 \mu \mathrm{g} / \mathrm{mL})$ and inner fruit bark $(20-100 \mu \mathrm{g} / \mathrm{mL})$. 
showed a strong radical scavenging activity while the other two (inner fruit bark and leave) extracts showed a low capacity as presented in Figure 1. This phenomenon might be attributed to their phenolic content as have been found by Rabeta et al. The high scavenging potential of Vitex negundo might be due to its high phenolic content in the methanolic extract (Rabeta et al., 2013). In this assay, vitamin $\mathrm{C}$ was used as positive control with $\mathrm{IC}_{50}$ of $5.05 \pm 0.02 \mu \mathrm{g} / \mathrm{mL}$.

The relationship between DFRS activity (Y) with total phenolic content revealed a coefficient of determination $\left(\mathrm{R}^{2}\right)$ of 0.7194 (Figure 2.). The result suggested that phenolic compounds have a significant correlation to the DPPH free radical scavenging activity of the extracts. Previous studies have explained the role of phenolic compounds with free hydroxyl group in scavenging DPPH free radicals. The higher phenolics content of the extracts, the stronger their scavenging activity (Siriwardhana and Shahidi, 2002; Khan et al., 2013; Dewi and Maryani, 2015).

\subsection{Alpha-glucosidase inhibitory (AGI) activity assay}

One approach in diabetes management is to maintain the normal blood glucose through inhibition of its absorption and metabolism. The AGI activity of the extracts were $0.58 \mu \mathrm{g} / \mathrm{mL}$ for DR extract, $1.55 \mu \mathrm{g} / \mathrm{mL}$ DT extract, and $64.43 \mu \mathrm{g} / \mathrm{mL}$ DIFB extract (presented in Table 2). The leaves extract did not show any inhibition against the enzyme. The AGI of durian part extracts varied but they were more potent (except leaves extract) than acarbose which was used as a positive control with $\mathrm{IC}_{50}$ of $781.63 \mu \mathrm{g} / \mathrm{mL}(0.782 \mathrm{mg} / \mathrm{mL})$. In the previous study performed by Telagari and Hullatti (2015) using the similar method, the acarbose activity has been examined and showed inhibitory activity with $\mathrm{IC}_{50}$ of $0.93 \mathrm{mg} / \mathrm{mL}$ (Telagari and Hullatti, 2015). The relationship between the concentration and AGI activity is as shown in Figure 3. In this study, the most potent alpha-glucosidase inhibitor extract was the DR extract, followed with DT and DIFB extracts. The DR and DT extracts had a potential activity based on their high content of phenolic compounds. Jang et al. (2015) and Choi et al. (2015) also reported that the root bark and twig extracts of mulberry revealed a high antioxidant and AGI activities due to its potential phenolic compounds.

\section{Conclusion}

The result of this study clearly demonstrated that phenolic compounds from DR and DT extracts contributed to their DFRS and AGI activities. The findings indicated that durian extracts especially DR and DT extracts could be considered as potential natural sources of antidiabetes and antioxidant agents.

\section{Conflict of interest}

The authors declare no conflict of interest

\section{Acknowledgement}

The authors acknowledge the Faculty of Pharmacy, Universitas Gadjah Mada for facilitating all instruments needed during this study.

\section{References}

Anthony, K.P. and Saleh, M.A. (2013). Free Radical Scavenging and Antioxidant Activities of Silymarin Components. Antioxidants, 2, 398-407. https:// doi.org/10.3390/antiox2040398

Choi, S.W., Lee, Y.J., Ha, S.B., Jeon, Y.H. and Lee, D.H. (2015). Evaluation of biological activity and analysis of functional constituents from different parts of Mulberry (Morus alba L.) Tree. Journal of Korean Society of Food Science and Nutrition, 44 (6), 823-831. https://doi.org/10.3746/ jkfn.2015.44.6.823

Dewi, R.T. and Maryani, F. (2015). Antioxidant and $\alpha$ Glucosidase Inhibitory Compounds of Centella Asiatica. Procedia Chemistry, 17, 147-152. https:// doi.org/10.1016/j.proche.2015.12.130

Dey, A. and Lakshmanan, J. (2013). The role of antioxidants and other agents in alleviating hyperglycemia mediated oxidative stress and injury in liver. Food and Function, 4(8), 1148-1152. https:// doi.org/10.1039/c3fo30317a

Hay, A.E., Aumond, M.C., Mallet, S., Dumontet, V., Litaudon, M., Rondeau, D. and Richomme, P. (2004). Antioxidant Xanthones from Garcinia vieillardii. Journal of Natural Products, 67(4), 707709. https://doi.org/10.1021/np0304971

Gülçin, I. (2012). Antioxidant activity of food constituents: An overview. Archives of Toxicology, 86(3), 345-391. https://doi.org/10.1007/s00204-0110774-2

Jang, Y.J., Leem, H.H., Jeon, Y.H., Lee, D.H. and Choi, S.W. (2015). Isolation and identification of alphaglucosidase inhibitors from Morus Root Bark. Journal of Korean Society of Food Science and Nutrition, 44(7), 1090-1099. http:// dx.doi.org/10.3746/jkfn.2015.44.7.1090

Kang, M.H., Lee, M.S., Choi, M.K., Min, K.S. and Shibamoto, T. (2012). Hypoglycemic activity of Gymnema sylvestre extracts on oxidative stress and antioxidant status in diabetic rats. Journal of Agricultural and Food Chemistry, 60(10), 2517- 
2524. https://doi.org/10.1021/jf205086b

Khan, M.A., Rahman, A.A., Islam, S., Khandokhar, P., Parvin, S., Islam, B. and Alam, A.H.M.K. (2013). A comparative study on the antioxidant activity of methanolic extracts from different parts of Morus alba L. (Moraceae). BMC Research Notes, 6(24), 19. https://doi.org/10.1186/1756-0500-6-24

Ministry of Health RI. (2012). Indonesian Herbal Pharmacopeia. Jakarta: Ministry of Health RI.

Nugroho A.E., Kusumaramdani G., Widyaninggar A., Anggoro D.P. and Pramono S. (2014). Antidiabetic effect of combinations of $n$-hexane insoluble fraction of ethanolic extract of Andrographis paniculata with other traditional medicine. International Food Research Journal, 21(2), 785-789.

Rabeta, M.S. and An Nabil, Z. (2013). Total phenolic and scavenging activity in Clitoria ternatea and Vitex negundo Linn. International Food Research Journal, 20(1), 495-500.

Siriwardhana, S.S.K.W. and Shahidi, F. (2002). Antiradical Activity of Extracts of Almond and Its By-products. Journal of the American Oil Chemist Society, 79(9), 903-908. https://doi.org/10.1007/ s11746-002-0577-4

Telagari, M. and Hullatti, K. (2015). In-vitro $\alpha$-amylase and $\alpha$-glucosidase inhibitory activity of Adiantum caudatum Linn. and Celosia argentea Linn. extracts and fractions. Indian Journal of Pharmacology, 47 (4), 425-429. https://doi.org/10.4103/02537613.161270

Yusro, F., Ohtani, K. and Kubota, S. (2016). Inhibition of $\alpha$-Glucosidase by Methanol Extracts from Wood Bark of Anacardiaceae, Fabaceae, Malvaceae and Phyllanthaceae Plants Family in West Kalimantan, Indonesia. 黒潮圏科学(Kuroshio Science), 9(2), 108-122. 